\title{
Endovascular Repair of the Thoracic Aorta
}

\author{
Grace J. Wang, M.D., ${ }^{1}$ and Ronald M. Fairman, M.D. ${ }^{1}$
}

The emergence of endovascular repair of the thoracic aorta (TEVAR) quickly followed the development of technology for the exclusion of infrarenal abdominal aortic aneurysms. Stent grafts comprised of metal struts covered with fabric made of Dacron/polyester or polytetrafluoroethylene were developed for the purpose of achieving an adequate seal at the proximal and distal aspects of thoracic aneurysms, thus excluding sac flow. The recognition of the decreased morbidity of this approach compared with open repair was readily apparent, as it avoided left thoracotomy, aortic cross-clamping, and left heart bypass. Since then, TEVAR is increasingly being used for other aortic pathologies such as complicated type B dissection, traumatic aortic transection, and aneurysmal disease extending into the arch or visceral segment, requiring debranching procedures.

KEYWORDS: Aneurysm, stent graft, thoracic

Objectives: Upon completion of this article, the reader should be able to identify the clinical applications for and complications associated with thoracic aortic stent grafting.

Accreditation: Tufts University School of Medicine (TUSM) is accredited by the Accreditation Council for Continuing Medical Education to provide continuing medical education for physicians.

Credit: TUSM designates this educational activity for a maximum of 1 AMA PRA Category 1 Credit $^{\text {TM }}$. Physicians should only claim credit commensurate with the extent of their participation in the activity.

\section{INDICATIONS FOR INTERVENTION}

The decreased morbidity of endovascular repair of the thoracic aorta (TEVAR) was detailed in numerous studies $^{1-5}$ and was the impetus for the multicenter Gore TAG pivotal trial, which led to U.S. Food and Drug Administration (FDA) approval for endovascular repair of descending thoracic aortic aneurysms in March 2005. ${ }^{1}$ The decision to proceed to surgery must weigh the risk of rupture against the risks of the operation and take into account the patient's projected survival. While a size cutoff of $6 \mathrm{~cm}$ has traditionally been accepted, surgeons have advocated for treatment of aneurysms as small as $5.5 \mathrm{~cm}$, given the decreased morbidity of this approach compared with open repair. Aneurysms growing $>1 \mathrm{~cm}$ per year or $>5 \mathrm{~mm}$ over a 6 -month period should also be treated. Other aortic pathologies that are increasingly being treated with TEVAR include traumatic aortic transection, type $\mathrm{B}$ dissection with malperfusion, intramural hematoma, penetrating aortic ulcer, and thoracoabdominal aneurysms with visceral artery debranching. Each of these will be mentioned in brief, but much of the chapter will be dedicated to the treatment of thoracic aneurysms; the three commercially available thoracic endografts were approved by the FDA for the treatment of thoracic aneurysms.

\section{Traumatic Aortic Transection}

Traumatic aortic transection typically occurs with highspeed, deceleration-type injuries and occurs at the level
${ }^{1}$ Division of Vascular Surgery and Endovascular Therapy, Hospital of the University of Pennsylvania, Philadelphia, Pennsylvania.

Address for correspondence and reprint requests: Grace Wang, M.D., Department of Surgery, Division of Vascular Surgery and Endovascular Therapy, Hospital of the University of Pennsylvania, 3400 Spruce Street, 4 Silverstein Pavilion, Philadelphia, PA 19104 (e-mail: grace.wang@uphs.upenn.edu).

Aortic Stent Grafts; Guest Editor, S. William Stavropoulos, M.D. Semin Intervent Radiol 2009;26:17-24. Copyright (C) 2009 by Thieme Medical Publishers, Inc., 333 Seventh Avenue, New York, NY 10001, USA. Tel: +1(212) 584-4662.

DOI 10.1055/s-0029-1208379. ISSN 0739-9529. 
of the ligamentum arteriosum. Thoracic stent deployment has been associated with significantly lower morbidity and mortality compared with open repair in the younger trauma population. ${ }^{6}$ Long-term data regarding the longevity of stent repair in this group are needed, as surgeons have pointed out stent-graft seal in the normal aorta is likely different from that in the aged, atherosclerotic aorta and bears more study. Smaller-diameter endovascular devices are also needed for this application.

\section{Type B Uncomplicated Dissection}

The INSTEAD trial (INvestigation of STEnt grafts in patients with type B Aortic Dissection) was a prospective, multicenter randomized trial conducted in Europe comparing optimal medical therapy to endovascular stent-graft placement for uncomplicated type B dissection. ${ }^{7}$ There was no significant difference in all-cause mortality at 1 year between groups. The preliminary conclusion of the trial was that careful monitoring and tailored antihypertensive therapy for these patients is justified. The one critique of the INSTEAD trial was that the study was designed to evaluate patients with more chronic dissections (56 days in stent-graft group versus 75 days in the medical management group). The ADSORB study, currently underway in Europe, will compare best medical management to stent grafting for patients with uncomplicated type B dissection presenting $\leq 14$ days after symptom onset.

\section{Type B Complicated Dissection}

Type B dissection with malperfusion has been successfully treated endovascularly, and treatment consists of covering the primary entry tear and reexpanding the true lumen. ${ }^{8,9}$ Assessment of the restoration of luminal flow to the true lumen can be performed with the use of intravascular ultrasound, which offers real-time information regarding the true and false lumina throughout the cardiac cycle.

\section{Penetrating Aortic Ulcer/Intramural Hematoma} Penetrating aortic ulcer/intramural hematoma is thought to be lesions lying within the spectrum of aortic dissection pathology, and treatment should consist of covering the intimal tear of any coexistent dissection, as well as exclusion of the aortic lesion. Although isolated penetrating ulcers are easy to cover with endovascular devices, it is unclear if extensive intramural hematoma is in fact a contraindication to this approach.

\section{Thoracoabdominal Aneurysms}

Although fenestrated and branched endograft technology is in development, these devices are well away from being approved for general use. Endovascular therapy of these aneurysms is thus hindered by the presence of the intervening visceral segment. Hybrid approaches consisting of "debranching" procedures have been developed to provide separate blood flow to the visceral arteries and allow coverage of the visceral segment. ${ }^{10,11}$ Although debranching procedures are not without morbidity, ${ }^{12}$ they may be a suitable option in patients in whom avoiding a thoracotomy or cardiopulmonary bypass is appropriate

\section{ANATOMY OF THE THORACIC AORTA}

The native thoracic aorta is of larger caliber than that of the infrarenal abdominal aorta, which necessitates the usage of larger-diameter stent grafts. Thoracic grafts are housed in large sheaths, which sometimes preclude conventional transfemoral access and require delivery through the distal common iliac artery, creation of an iliac artery conduit, and, at times, direct delivery through the abdominal aorta. In addition, the high force of blood flow in the thoracic aorta requires a longer seal zone $(20 \mathrm{~mm})$ on either end to prevent displacement. The curve of the thoracic aorta at the arch presents special challenges in attempting to achieve adequate proximal fixation and seal. Radial support must be weighed against the need for enough flexibility and conformability within the device to navigate this curve and achieve seal following deployment. The angulation of the aorta often progresses with age, as atherosclerotic changes lead to lengthening and increased tortuosity, adding to the difficulty of accurate device deployment and adequate proximal landing. When device deployment is performed close to or within the arch, the graft must closely appose the "inner curve" of the arch. If the proximal end of the graft is oriented toward the apex of such a curve, "birdbeaking," where the graft is not apposed to the aortic wall, will occur, increasing the risk of graft collapse, migration, and failure of aneurysm exclusion. With adequate preoperative planning and anticipation of these difficulties, however, these issues can usually be circumvented by landing more proximally and debranching the arch as needed.

\section{PROXIMAL AND DISTAL LANDING ZONES}

The proximal landing zone abuts or involves branch vessels of the arch, namely the brachiocephalic trunk, left common carotid artery, and left subclavian artery. To achieve the $20-\mathrm{mm}$ proximal seal required and to ensure that the graft will sit in close apposition to the inner curve of the arch, debranching procedures can be performed, which essentially "move" the branch vessels to a more proximal location, allowing coverage of the origins of these vessels. When coverage of the left subclavian artery is required, duplex of the vertebral and carotid arteries should be completed to determine whether left 
common carotid-left subclavian bypass or left subclavian transposition is in order. For more proximal landing zones involving the left common carotid artery or brachiocephalic trunk, antegrade bypass from the ascending aorta/transposition of the great vessels can be performed, ${ }^{13-16}$ or alternatively, extra-anatomic bypass can be performed to avoid sternotomy. ${ }^{17}$ The distal landing zone also must be at least $20 \mathrm{~mm}$ in length. Typically, the celiac axis is spared, although reports of covering the celiac artery in patients with a documented patent pancreaticoduodenal arcade have been successful in achieving up to an additional $25 \mathrm{~mm}$ in seal length with nominal incidence of mesenteric ischemia. ${ }^{17,18}$

\section{PREOPERATIVE PLANNING}

Computed tomographic angiography (CTA) of the chest, abdomen, and pelvis with three-dimensional reformatting provides accurate and pertinent information regarding the diameter of the aorta to be used for the proximal and distal seal zones, the length of coverage required, the degree of angulation and tortuosity of the aorta, as well as characteristics of the lumen and wall of the aorta, including thrombus burden and calcification. Additionally, the diameter of the external iliacs and the degree of calcification/tortuosity from the femoral vessels, through the iliacs, to the aortic bifurcation should be noted and a decision should be made whether to proceed with transfemoral or alternative access. From this information, the diameter and length of the graft(s) are chosen, keeping in mind the degree of oversizing specified in that device's instructions for use. Magnetic resonance angiography (MRA) can also be used, but the degree of anatomic detailing is no better, and because of the risk of nephrogenic systemic fibrosis in patients with end-stage renal disease (ESRD) or chronic renal insufficiency, ${ }^{19}$ affords no benefit compared with CTA. MRA also fails to depict vessel wall calcification, which has implications for vascular access.

\section{AVAILABLE ENDOGRAFTS FOR TEVAR}

An overview of the different devices in use is provided below. $^{20}$

The Gore-TAG device is the first stent graft device approved by the FDA for treatment of descending thoracic aneurysms. It is made of expanded polytetrafluoroethylene and an exoskeleton made of nitinol. The proximal and distal ends of the graft have scalloped flares, which are thought to allow for conformity and better apposition to the tortuous aorta (Fig. 1).

The Medtronic Talent device was studied in the VALOR I trial (Vascular Talent Thoracic Stent Graft System for the Treatment of Thoracic Aortic Aneurysms), which proved its clinical efficacy. It is made of two components, a proximal straight tubular

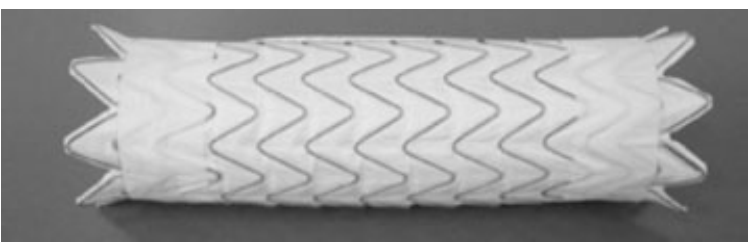

Figure 1 Gore TAG endoprosthesis (W.L. Gore and Associates, Inc., Flagstaff, AZ).

stent graft with a proximal bare stent configuration, and a distal tapered tubular stent graft with an open web proximal configuration and closed web distal configuration. It consists of a woven polyester graft with a nitinol endoskeleton (Fig. 2). The Talent device was widely
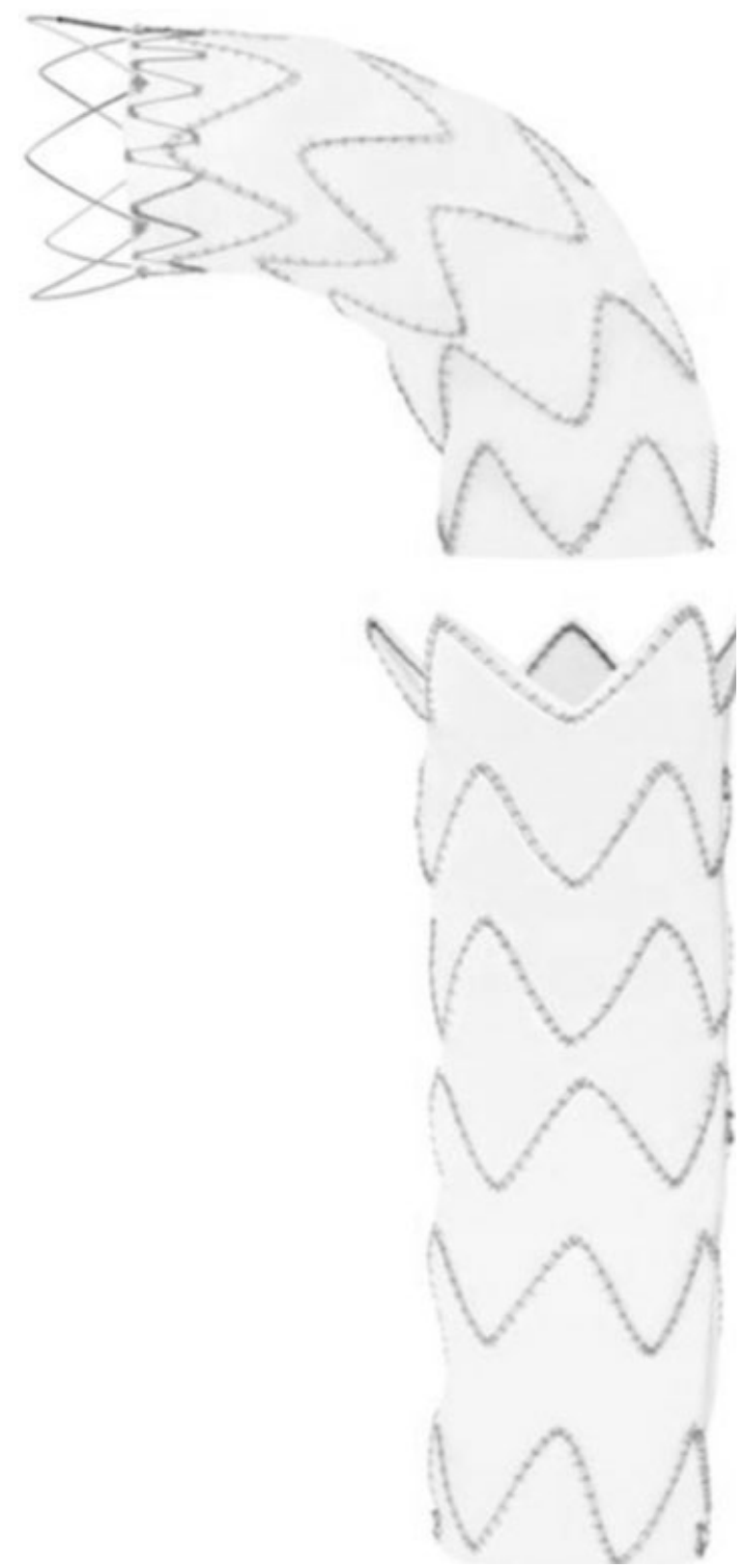

Figure 2 Medtronic Talent stent graft (Medtronic, Minneapolis, MN). 


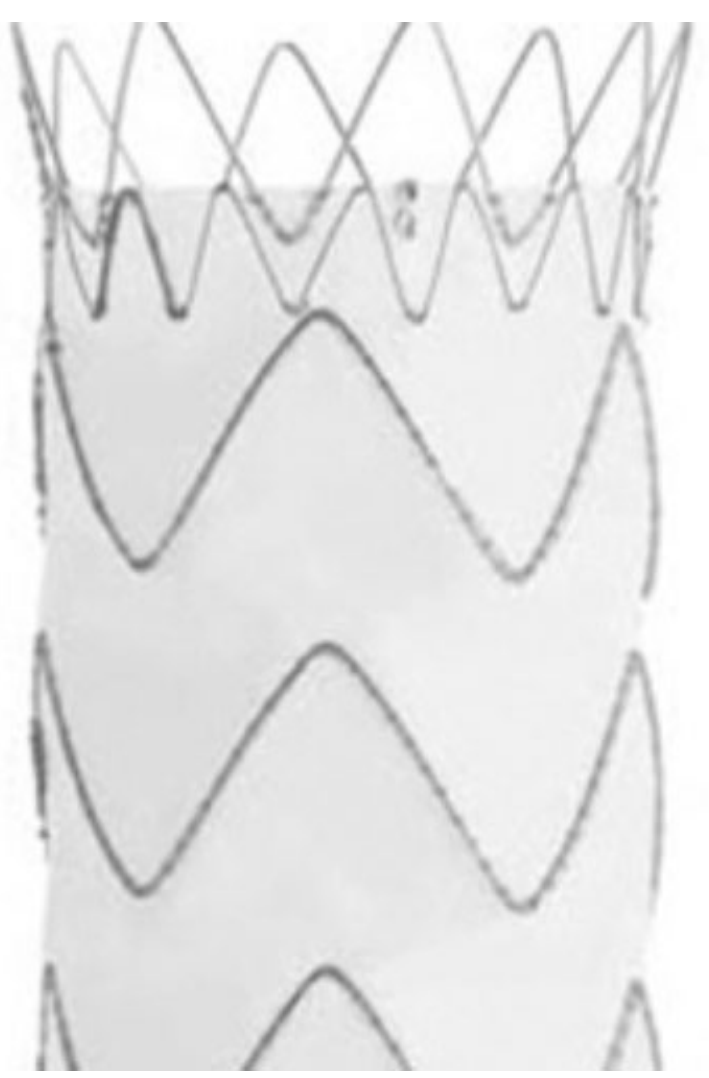

Figure 3 Medtronic Valiant stent graft.

utilized outside of the United States for several years and spurred the development of its next-generation version, the Valiant endograft, currently being tested for efficacy in the VALOR II trial

The Medtronic Valiant endograft (Fig. 3) has a modified proximal bare stent configuration with eight bare peak wires compared with the five bare peak wires found in the Talent stent graft. The long connecting bar of the Talent device was removed in the Valiant device to afford better flexibility of the device. Columnar support has also been optimized through stent spacing, and longer covered devices are now an option.

The Cook TX2 stent graft is a two-piece modular endograft system made of proximal and distal tubular endografts. The proximal endograft is covered and has stainless steel barbs allowing for active fixation to the aortic wall. The distal component has at its distal end a bare metal stent similar to the suprarenal stent in the Zenith device for endovascular repair of abdominal aortic aneurysm (AAA). This allows active fixation of the device over the origins of the visceral vessels. The TX2 is made of Dacron fabric covered by stainless steel Z-stents (Fig. 4). Both the Medtronic Talent and Cook TX2 thoracic endografts were recently approved for commercial use by the FDA.

The Bolton Relay stent graft (Fig. 5) is a relatively new investigational device used for the treatment of thoracic aortic pathologies. It is composed of self-expanding nitinol stents sutured to a polyester fabric graft with a

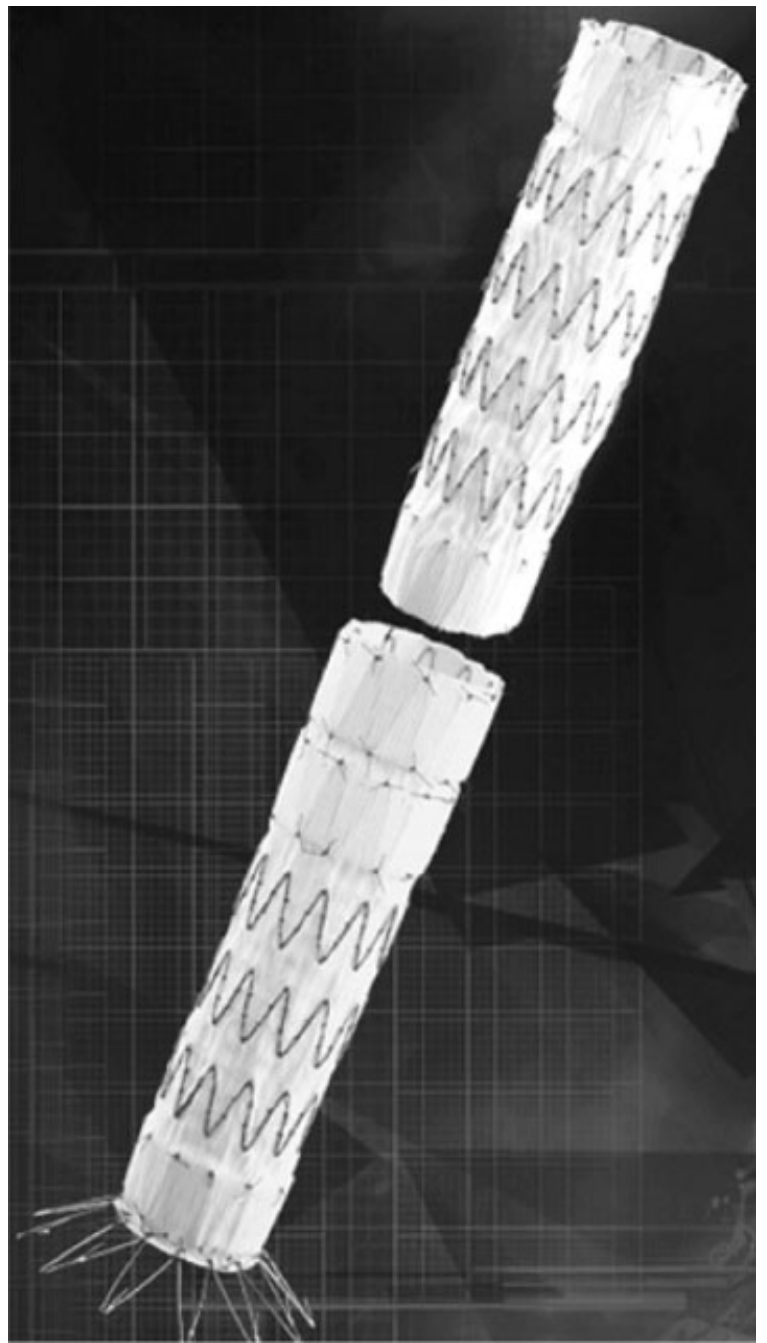

Figure 4 Cook TX2 stent graft (Cook Medical, Inc. Bloomington, IN).

curved longitudinal nitinol wire intended to provide columnar strength. It has a proximal bare stent, which remains constrained until the endograft is fully deployed. A study in the United States is currently underway.

\section{CONDUCT OF THE OPERATION}

The procedure is typically done under general endotracheal anesthesia. A lumbar drain is placed in cases where extensive coverage of the thoracic aorta is anticipated, where interruption of contributing blood supply to the artery of Adamkiewicz (T8-L1) is high, and in cases where the patient has had prior AAA repair. Lumbar drainage of cerebrospinal fluid to decrease the pressure in the subarachnoid space and increase the spinal cord perfusion pressure has been found to be an important adjunct in preventing paraplegia following TEVAR. ${ }^{21,22}$ Neuromonitoring in the form of somatosensory-evoked potentials (SSEPs) provides real-time functional information about the spinal cord. Any decrease in amplitude of SSEPs during the procedure will prompt maneuvers 


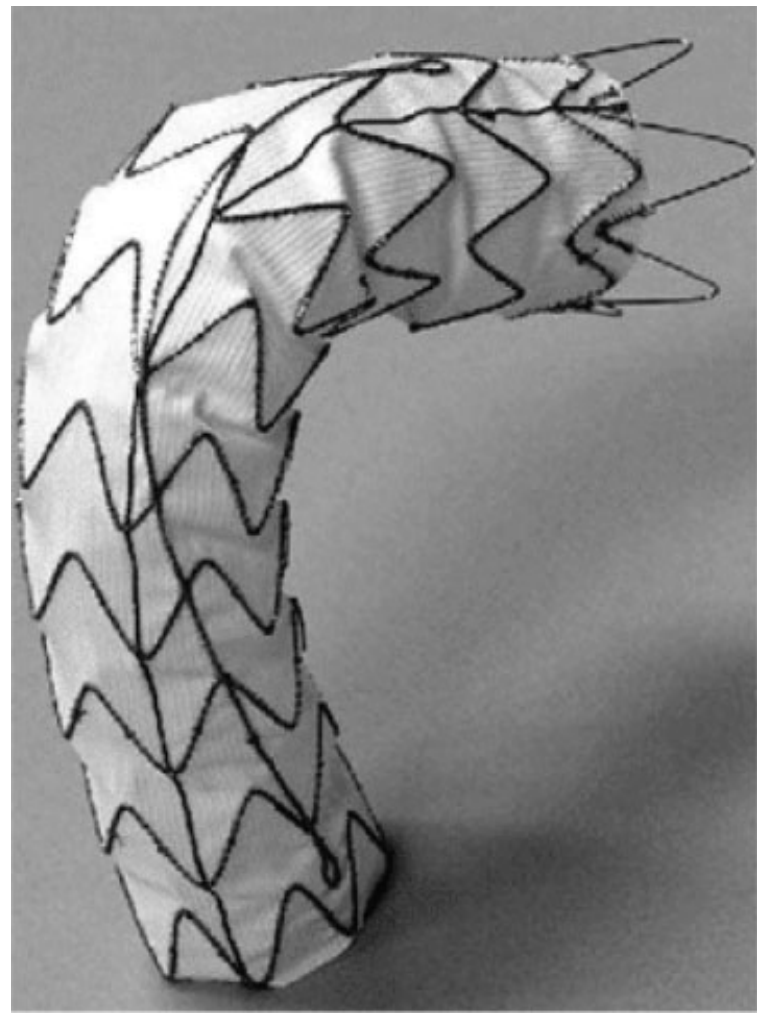

Figure 5 Bolton Relay stent graft (Bolton Medical, Milan, Italy).

to increase the mean arterial pressure and cerebrospinal fluid drainage. Performance of the procedure requires the delivery of a large-bore sheath into the aorta as well as angiographic access. Typically this is accomplished transfemorally, although patients presenting with disadvantaged femoral access sites may require delivery of the sheath through the common iliac artery, an iliac conduit, and so on. To land a device accurately in the arch, positioning of the $\mathrm{C}$-arm in the left anterior oblique position at 45 to 75 degrees will "splay out" the arch branches so that accurate device deployment is achieved. Even with the stent graft perfectly positioned, deployment of the graft can be complicated secondary to the high volume of blood flow in the thoracic aorta and the potential for the "windsock effect," which describes the tendency for the graft to be pulled distally before deployment is complete. Described maneuvers to circumvent this phenomenon include rapid right ventricular pacing, controlled hypotension, and adenosine-induced cardiac arrest. ${ }^{23}$ Once the device is deployed, the stent graft is typically ballooned at the seal zones and graft junctions, and completion angiography is performed to ensure effective sac exclusion and preservation of essential vessels and to detect any evidence of endoleak.

Type I endoleak: Involves the proximal or distal seal zones. Further ballooning or placement of another graft may be necessary to achieve seal. Vigorous proximal ballooning may be hazardous; retrograde proximal aortic dissection has been reported.

Type II endoleak: Unusual in the thoracic aorta, but due to retrograde flow from intercostal arteries into the sac. Typically resolves with conservative management.

Type III endoleak: Occurs with inadequate overlap and seal between modular components. Usually responds with further ballooning or additional graft or stent placement.

Type IV endoleak: Occurs due to porosity of the graft, which is a rare occurrence with current-generation devices.

Type V endoleak: Otherwise known as "endotension," occurs in the setting of continued sac expansion despite absence of an identifiable endoleak on subsequent imaging studies.

Once exclusion of the sac has been confirmed, the device sheath is removed, and the arteriotomy is repaired.

\section{COMPLICATIONS}

\section{Stroke and Paraplegia}

Because the proximal seal zone is in proximity to the carotid arteries, embolic strokes in the distribution of the middle cerebral artery can occur following TEVAR. Risk factors for embolic stroke include the need for proximal deployment of the graft, presence of mobile atheromata in the arch, as well as prior stroke. ${ }^{24}$ In addition, the vertebral arteries arising from the subclavian may be the source for posterior circulation strokes. ${ }^{25}$ Planned coverage of the left subclavian in a patient with a dominant left vertebral, hypoplastic right vertebral, or incomplete circle of Willis should be preceded by carotid subclavian bypass, as interruption of blood flow in these circumstances has been associated with an increased incidence of stroke and paraplegia. ${ }^{25-27}$ Left upperextremity symptoms occurred in up to $15.8 \%$ of patients in one study, but only required intervention in a minority of patients (5.3\%), supporting expectant management in the majority of cases. ${ }^{28}$ Extensive coverage of the thoracic aorta ${ }^{29,30}$ as well as prior history of AAA repair, ${ }^{30,31}$ places the patient at increased risk for paraplegia.

\section{Visceral Ischemia}

Visceral ischemia can occur with intentional coverage of the celiac axis, although reports have suggested that documentation of an intact pancreaticoduodenal arcade preoperatively reduces this risk. ${ }^{17}$

\section{Access Complications}

Because of the obligatory large sheath size for delivery of the device, passage of the sheath through a 
small-diameter, tortuous, or excessively calcified external iliac artery can lead to iliac artery disruption. Intra-aortic balloon control helps to stabilize the patient until proximal and distal control of the iliac artery and definitive repair can be conducted. Anticipation of the need for adjunctive access measures is thus important and is required in a significant percentage of patients, ranging from 9.4 to $23.8 \%$ in published reports. ${ }^{3,5}$ From the percutaneous angiography puncture site, a pseudoaneurysm or hematoma may form.

\section{Postimplantation Syndrome}

This syndrome occurs during the early postoperative period and is characterized by leukocytosis, fever, and elevation of inflammatory mediators such as $\mathrm{C}$-reactive protein, interleukin-6, and tumor necrosis factor- $\alpha$. $^{32-34}$ It is thought to be due to endothelial activation by the endoprosthesis. For thoracic aortic stent grafts, development of either unilateral or bilateral reactive pleural effusions is not uncommon, with a reported incidence of 37 to $73 \%$. $^{33,35,36}$

\section{Device Migration and Endoleak}

Migration of the graft $(>10 \mathrm{~mm}$ ) caudally can occur, with a published incidence of 1 to $2.8 \% .^{2,3,37}$ Factors predisposing to migration include excessive oversizing and tortuous seal zone anatomy. The incidence of endoleak following thoracic aortic stent placement is less common that that for EVAR and is estimated at 3.9 to $15.3 \% .^{2,3,37,38}$

Other complications that may occur include myocardial infarction and respiratory/aspiration events, underscoring the predominance of medical comorbidities in the patients with significant vascular disease.

\section{POSTOPERATIVE MANAGEMENT/ SURVEILLANCE}

The patients are initially monitored in the intensive care unit setting, paying special attention to the neurological exam to detect evidence of stroke or paraplegia, and evidence of visceral ischemia in those individuals who required coverage of the celiac axis for distal landing zone length. Patients are typically transferred from the unit to the floor on postoperative day 3 and discharged within a week. Surveillance consists of CTA at 1 month, 6 months, then annually postoperatively.

\section{CLINICAL OUTCOME}

Technical success in various reports has been high, approaching 98\%. ${ }^{2,3}$ Perioperative mortality is low, ranging from 1.9 to $2.1 \% .^{2,3,37}$ This is in contrast to a reported 5.7 to $11.7 \%$ in the respective open repair arm.
Perioperative stroke has ranged from 4 to $8 \% .^{39-41}$ Spinal cord ischemia manifesting as paraplegia or paraparesis has been reported to be 3 to $5.6 \%{ }^{2,3}$ In a recent study in which perioperative morbid events including myocardial infarction, respiratory events, stroke, and paraplegia were combined into a composite score, the percentage of patients who experienced at least one event was over a third lower in the TEVAR group compared with the open repair arm (9.4\% versus $33 \%, p<0.01)^{3}$

The incidence of endoleak at 5-year follow-up with the Gore TAG device was 4.3\%, with type I attachment site leaks being the most common type. Effective aneurysm exclusion was achieved in the majority of patients, with only a $2.8 \%$ aneurysm-related mortality at 5 years.

\section{LONG-TERM SURVEILLANCE}

Clinical follow-up for thoracic aortic stent grafts is in its infancy, but despite the not insignificant rate of secondary intervention required following stent grafting (3.6 to $4.4 \%),{ }^{3,37}$ the greatly decreased morbidity of this approach makes it preferable to open repair in the majority of cases. A CTA is usually obtained within a month of the procedure, followed by an imaging study at 6 months and annually thereafter. Evidence of attachment site endoleak is intervened upon promptly. Type II endoleaks can be observed provided that the sac does not enlarge. MRA can also be used, although it is of limited applicability in patients with ESRD or chronic renal insufficiency. Noncontrast computed tomography allows for measurement of the sac diameter and is sufficient in most circumstances to document effective aneurysm exclusion.

\section{REFERENCES}

1. Makaroun MS, Dillavou ED, Kee ST, et al. Endovascular treatment of thoracic aortic aneurysms: results of the phase II multicenter trial of the GORE TAG thoracic endoprosthesis. J Vasc Surg 2005;41:1-9

2. Bavaria JE, Appoo JJ, Makaroun MS, Verter J, Yu ZF, Mitchell RS. Endovascular stent grafting versus open surgical repair of descending thoracic aortic aneurysms in low-risk patients: a multicenter comparative trial. J Thorac Cardiovasc Surg 2007;133:369-377

3. Matsumura JS, Cambria RP, Dake MD, Moore RD, Svensson LG, Snyder S. International controlled clinical trial of thoracic endovascular aneurysm repair with the Zenith TX2 endovascular graft: 1-year results. J Vasc Surg 2008;47:247-257; discussion 257

4. Najibi S, Terramani TT, Weiss VJ, et al. Endoluminal versus open treatment of descending thoracic aortic aneurysms. J Vasc Surg 2002;36:732-737

5. Stone DH, Brewster DC, Kwolek CJ, et al. Stent-graft versus open-surgical repair of the thoracic aorta: mid-term results. J Vasc Surg 2006;44:1188-1197 
6. Demetriades D, Velmahos GC, Scalea TM, et al. Operative repair or endovascular stent graft in blunt traumatic thoracic aortic injuries: results of an American Association for the Surgery of Trauma Multicenter Study. J Trauma 2008;64: 561-570; discussion 570-571

7. Nienaber CA, Zannetti S, Barbieri B, Kische S, Schareck W, Rehders TC. INvestigation of STEnt grafts in patients with type B Aortic Dissection: design of the INSTEAD trial-a prospective, multicenter, European randomized trial. Am Heart J 2005;149:592-599

8. Kaya A, Heijmen RH, Overtoom TT, Vos JA, Morshuis WJ, Schepens MA. Thoracic stent grafting for acute aortic pathology. Ann Thorac Surg 2006;82:560-565

9. Duebener LF, Lorenzen P, Richardt G, et al. Emergency endovascular stent-grafting for life-threatening acute type B aortic dissections. Ann Thorac Surg 2004;78:1261-1266; discussion 1266-1267

10. Black SA, Wolfe JH, Clark M, Hamady M, Cheshire NJ, Jenkins MP. Complex thoracoabdominal aortic aneurysms: endovascular exclusion with visceral revascularization. J Vasc Surg 2006;43:1081-1089; discussion 1089

11. Bockler D, Kotelis D, Geisbusch P, et al. Hybrid procedures for thoracoabdominal aortic aneurysms and chronic aortic dissections: a single center experience in 28 patients. J Vasc Surg 2008;47:724-732

12. Greenberg RK, Lytle B. Endovascular repair of thoracoabdominal aneurysms. Circulation 2008;117:2288-2296

13. Szeto WY, Bavaria JE, Bowen FW, Woo EY, Fairman RM, Pochettino A. The hybrid total arch repair: brachiocephalic bypass and concomitant endovascular aortic arch stent graft placement. J Card Surg 2007;22:97-102; discussion 103104

14. Zhou W, Reardon M, Peden EK, Lin PH, Lumsden AB. Hybrid approach to complex thoracic aortic aneurysms in high-risk patients: surgical challenges and clinical outcomes. J Vasc Surg 2006;44:688-693

15. Bergeron P, Mangialardi N, Costa P, et al. Great vessel management for endovascular exclusion of aortic arch aneurysms and dissections. Eur J Vasc Endovasc Surg 2006; 32:38-45

16. Chuter TA, Schneider DB, Reilly LM, Lobo EP, Messina LM. Modular branched stent graft for endovascular repair of aortic arch aneurysm and dissection. J Vasc Surg 2003;38: 859-863

17. Vaddineni SK, Taylor SM, Patterson MA, Jordan WD Jr. Outcome after celiac artery coverage during endovascular thoracic aortic aneurysm repair: preliminary results. J Vasc Surg 2007;45:467-471

18. Jorna FH, Verhoeven EL, Bos WT, Prins TR, Dol JA, Reijnen MM. Treatment of a ruptured thoracoabdominal aneurysm with a stent-graft covering the celiac axis. J Endovasc Ther 2006;13:770-774

19. Grobner T, Prischl FC. Patient characteristics and risk factors for nephrogenic systemic fibrosis following gadolinium exposure. Semin Dial 2008;21:135-139

20. Lin PH, El Sayed HF, Kougias P, Zhou W, LeMaire SA, Coselli JS. Endovascular repair of thoracic aortic disease: overview of current devices and clinical results. Vascular 2007;15:179-190

21. Cheung AT, Weiss SJ, McGarvey ML, et al. Interventions for reversing delayed-onset postoperative paraplegia after thoracic aortic reconstruction. Ann Thorac Surg 2002;74: 413-419; discussion 420-421
22. Khoynezhad A, Donayre CE, Bui H, Kopchok GE, Walot I, White RA. Risk factors of neurologic deficit after thoracic aortic endografting. Ann Thorac Surg 2007;83:S882-S889; discussion S890-S892

23. Nienaber CA, Kische S, Rehders TC, et al. Rapid pacing for better placing: comparison of techniques for precise deployment of endografts in the thoracic aorta. J Endovasc Ther 2007;14:506-512

24. Gutsche JT, Cheung AT, McGarvey ML, et al. Risk factors for perioperative stroke after thoracic endovascular aortic repair. Ann Thorac Surg 2007;84:1195-1200; discussion 1200

25. Feezor RJ, Martin TD, Hess PJ, et al. Risk factors for perioperative stroke during thoracic endovascular aortic repairs (TEVAR). J Endovasc Ther 2007;14:568-573

26. Woo EY, McGarvey M, Jackson BM, Bavaria JE, Fairman RM, Pochettino A. Spinal cord ischemia may be reduced via a novel technique of intercostal artery revascularization during open thoracoabdominal aneurysm repair. J Vasc Surg 2007;46:421-426

27. Noor N, Sadat U, Hayes PD, Thompson MM, Boyle JR. Management of the left subclavian artery during endovascular repair of the thoracic aorta. J Endovasc Ther 2008;15:168-176

28. Riesenman PJ, Farber MA, Mendes RR, Marston WA, Fulton JJ, Keagy BA. Coverage of the left subclavian artery during thoracic endovascular aortic repair. J Vasc Surg 2007;45:90-94; discussion 94-95

29. Amabile P, Grisoli D, Giorgi R, Bartoli JM, Piquet P. Incidence and determinants of spinal cord ischaemia in stentgraft repair of the thoracic aorta. Eur J Vasc Endovasc Surg 2008;35:455-461

30. Buth J, Harris PL, Hobo R, et al. Neurologic complications associated with endovascular repair of thoracic aortic pathology: incidence and risk factors. A study from the European Collaborators on Stent/Graft Techniques for Aortic Aneurysm Repair (EUROSTAR) registry. J Vasc Surg 2007;46:1103-1110; discussion 1110-1111

31. Cheung AT, Pochettino A, McGarvey ML, et al. Strategies to manage paraplegia risk after endovascular stent repair of descending thoracic aortic aneurysms. Ann Thorac Surg 2005;80:1280-1288; discussion 1288-1289

32. Gabriel EA, Locali RF, Romano CC, Duarte AJ, Palma JH, Buffolo E. Analysis of the inflammatory response in endovascular treatment of aortic aneurysms. Eur J Cardiothorac Surg 2007;31:406-412

33. Ishida M, Kato N, Hirano T, Shimono $T$, Shimpo $H$, Takeda K. Thoracic CT findings following endovascular stent-graft treatment for thoracic aortic aneurysm. J Endovasc Ther 2007;14:333-341

34. Eggebrecht H, Mehta RH, Metozounve H, et al. Clinical implications of systemic inflammatory response syndrome following thoracic aortic stent-graft placement. J Endovasc Ther 2008;15:135-143

35. Sakai T, Dake MD, Semba CP, et al. Descending thoracic aortic aneurysm: thoracic CT findings after endovascular stent-graft placement. Radiology 1999;212:169-174

36. Schoder M, Cartes-Zumelzu F, Grabenwoger M, et al. Elective endovascular stent-graft repair of atherosclerotic thoracic aortic aneurysms: clinical results and midterm follow-up. AJR Am J Roentgenol 2003;180:709-715

37. Makaroun MS, Dillavou ED, Wheatley GH, Cambria RP. Five-year results of endovascular treatment with the Gore TAG device compared with open repair of thoracic aortic aneurysms. J Vasc Surg 2008;47:912-918 
38. Preventza O, Wheatley GH III, Ramaiah VG, et al. Management of endoleaks associated with endovascular treatment of descending thoracic aortic diseases. J Vasc Surg 2008;48:69-73

39. Demers P, Miller DC, Mitchell RS, et al. Midterm results of endovascular repair of descending thoracic aortic aneurysms with first-generation stent grafts. J Thorac Cardiovasc Surg 2004;127:664-673
40. Svensson LG. Device discordancy: lost cords, quick-fix seekers, quality, and ethics. J Thorac Cardiovasc Surg 2006; 131:261-263

41. Dake MD, Miller DC, Mitchell RS, Semba CP, Moore KA, Sakai T. The "first generation" of endovascular stent-grafts for patients with aneurysms of the descending thoracic aorta. J Thorac Cardiovasc Surg 1998;116:689-703; discussion 703-704 